\title{
3 Research Square

\section{Ischemic stroke with a preceding Trans ischemic attack(TIA) less than 24 hours: Predicting clinical risk factors for thrombolytic therapy}

Nicolas Poupore

University of South Carolina School of Medicine Greenville Campus

Dan Strat

University of South Carolina School of Medicine Greenville Campus

Tristan Mackey

Prisma Health

Ashley Snell

University of South Carolina School of Medicine Greenville Campus

Thomas Nathaniel ( $\nabla$ nathanit@greenvillemed.sc.edu )

University of South Carolina School of Medicine Greenville Campus https://orcid.org/0000-0003-09545050

Research article

Keywords: Ischemic, stroke, trans ischemic attack, clinical risk factors, thrombolytic therapy

Posted Date: November 12th, 2019

DOI: https://doi.org/10.21203/rs.2.17137/v1

License: (1) This work is licensed under a Creative Commons Attribution 4.0 International License.

Read Full License 


\section{Abstract}

Background Acute ischemic stroke attack with and without a recent TIA within or less than 24 hours may differ in clinical risk factors, and this may affect treatment outcomes following thrombolytic therapy. We examined whether the odds of exclusion or inclusion for thrombolytic therapy are greater in ischemic stroke with TIA less than 24 hours preceding ischemic stroke(TIA-24hr-ischemic stroke patients) as compared to those without recent TIA or non-TIA $<24$ hours.

Methods A retrospective hospital-based analysis was conducted on 6,315 ischemic stroke patients, of whom 846 had proven brain diffusion-weighted magnetic resonance imaging (DW-MRI) of an antecedent TIA within 24 hours prior to ischemic stroke. The logistic regression model was developed to generate odds ratios (OR) to determine clinical factors that may increase the likelihood of exclusion or inclusion for thrombolytic therapy. The validity of the model was tested using a Hosmer-Lemeshow test, while the Receiver Operating Curve (ROC) was used to test the sensitivity of our model.

Results In TIA-24hr-ischemic stroke population, patients with a history of alcohol abuse (OR $=5.525,95 \%$ $\mathrm{Cl}, 1.003-30.434, p=0.05)$, migraine (OR=4.277, $95 \% \mathrm{Cl}, 1.095-16.703, p=0.037)$, and increasing NIHSS score (OR=1.156, 95\% Cl, 1.058-1.263, $p=0.001)$ were associated with the increasing odds of receiving rtPA, while older patients $(\mathrm{OR}=0.965,95 \% \mathrm{Cl}, 0.934-0.997, \mathrm{P}=0.033)$ were associated with the increasing odds of not receiving rtPA.

Conclusion In TIA-24hr-ischemic stroke patients, older patients with higher INR values are associated with increasing odds of exclusion from thrombolytic therapy. Our findings demonstrate clinical risks factors that can be targeted to improve the use and eligibility for rtPA in in TIA-24hr-ischemic stroke patients.

\section{Introduction}

There is a general concern that Transient Ischemic Attack (TIA) patients with focal lesions, which may appear normal on computed tomography (CT), may be at higher risk for hemorrhage post-thrombolysis treatment following onset of ischemic stroke [1-5]. More than one third of symptomatic patients within the 24-hour time frame may present with a number of cerebral infarcts and could be misdiagnosed and classified as a TIA[6], especially if no lesion is observed on the CT scan[7]. It has been shown that the use of CT as a diagnostic tool may not detect TIA-associated focal lesions prior to rtPA therapy in TIAischemic stroke patients [8]. This is because in some patients with a TIA preceding acute ischemic stroke (TIA-ischemic stroke) especially within 24 hour of stroke onset, the TIA may appear invisible on CT scans, even with ischemic lesions, and this could affect treatment outcome with thrombolytic therapy[9$11]$.

The presence of a focal lesion on DW-MRI is an important factor in the classification of transitory focal neurological dysfunction as a TIA [12-15], and represents a contraindication for rtPA therapy [16]. The new tissue-based description of a TIA as a transient episode of neurological dysfunction without acute infarction is not a contraindication for rtPA in TIA-ischemic stroke patients[17]. We know that ischemic 
patients with an established TIA less than 24 hours differ in clinical variables when compared with those without a TIA [2]. Patients with an established TIA more than 24 hours prior to stroke will normally receive treatment and may be admitted because of the TIA, allowing a timely administration of rtPA[1, 2]. We also know that baseline clinical risk factors in TIA-24hr-ischemic stroke patients may affect treatment outcomes following thrombolytic therapy [18]. It is unknown whether specific clinical risk factors in ischemic stroke patients with a TIA within 24 hours preceding an acute ischemic stroke may contribute to the inclusion or exclusion from rtPA therapy.

Data are lacking on the effect of specific clinical risk factors associated with inclusion or exclusion for rtPA therapy in ischemic stroke patients of a TIA that sets in within or less than 24 hours preceding ischemic stroke TIA-24hr-ischemic stroke patients). It is possible that clinical risk factors associated with ischemic stroke patients with a TIA within or less than 24 hours preceding an acute ischemic stroke may be different from ischemic stroke patients without a TIA or with an established TIA. Since a TIA within 24 hours preceding ischemic stroke is not an established contraindication for rtPA, it implies that the presence or absence of specific clinical risk factors in acute ischemic stroke patients with TIA may contribute to the exclusion or inclusion of patients for rtPA therapy. In this study, we tested the hypothesis that specific baseline clinical risk factors may impact the inclusion or exclusion of TIA-24hr-ischemic stroke patients for rtPA therapy. The objective of the present study was to identify specific demographic and clinical risk factors associated with inclusion or exclusion from rtPA therapy in an ischemic stroke population with a TIA within 24 hours preceding an acute ischemic stroke. Knowledge of such clinical risk factors would be clinically relevant in decision making, especially in developing management and treatment strategy in the population of stroke patients with established TIA within or less than 24 hours preceding ischemic stroke.

\section{Methods}

\subsection{Study population}

Data from ischemic stroke patients admitted to the PRISMA Health Greenville, SC, USA between January 2010 and June 2016 were used for this study. The ethics committee of PRISMA Health approved this retrospective study. Patients that presented with ischemic stroke within 24 hours of symptom onset, based on relevant ischemic lesions on CT or brain MRI, were included in the analysis. Ischemic stroke patients were divided into two groups: the first group comprises of those with a TIA within or less than 24 hours preceding ischemic stroke (TIA-24hr-ischemic stroke patients), while the second group consists of those with previously diagnosed TIA (at least one month) or no history of TIA (non-TIA $<24$ hours). For the first group, identified TIA patients prior to stroke with DWI abnormalities consistent with focal neurological dysfunction were excluded. In both groups, patients with symptomatic intracerebral hemorrhage $(\mathrm{SICH})$ were excluded. 
Data on clinical characteristics and laboratory analysis were collected directly from the stroke registry, which has been described in previous studies [19-22]. Collected data included patients' medical history, including atrial fibrillation/atrial flutter, coronary artery disease (CAD), carotid stenosis, pregnancy, depression, diabetes, drug or alcohol abuse, dyslipidemia, family history of stroke, congestive heart failure (CHF), hormone replacement therapy (HRT), hypertension, migraine, obesity, prior stroke, prior TIA, prosthetic heart valve, peripheral vascular disease (PVD), chronic renal disease, sickle cell, sleep apnea, and history of smoking. Demographic variables data were collected include age, race and gender. Further, data on medication history and stroke severity (NIHSS) score were also obtained.

\section{2 | Statistical analysis}

All statistical analyses were performed using the SPSS Statistics Software version 15.0 (Chicago, IL). Descriptive statistics were used to analyze demographic and clinical risk factors in ischemic stroke patients characterized based on a TIA-24hr-ischemic stroke patients and non-TIA $<24$-hour patients. The Pearson $\chi 2$ test or Student's $t$ test was utilized to perform a bivariate group comparison of baseline characteristics between the two groups. For continuous variables, a Student- $t$ test was used, while Pearson's chi squared analyses was considered for analyzing discrete variables. In order to examine clinical factors associated with inclusion for rtPA, a multivariable binary logistic regression was performed. Our primary outcome measures for regression analysis were clinical risk factors that are significantly associated with exclusion of inclusion for rtPA therapy. This approach provided the opportunity to determine whether the association between specific clinical risk factors in the TIA-24hrischemic stroke patients and the non-TIA <24-hour patients are associated with inclusion or exclusion for rtPA(the non-TIA <24-hour group). For the logistic regression, the variable selection for a multivariate model was not based on univariate p-values, because we considered clinical knowledge to supersede univariate statistical analysis of $p$-values when selecting variables for model building [23]. Therefore, the backward selection method allowed all of our variables to be selected, while removing the least significant one at each step. In general, our analysis identified variables independently associated with the increasing odds (odds ratios [OR]) and their $95 \%$ Cis of exclusion or inclusion for thrombolytic therapy in patients with and without a TIA 24 hours prior to ischemic stroke.

In the regression model, rtPA treatment served as the dependent variable. In addition, variables for TIA24hr-ischemic stroke patients were included as the primary independent for the entire ischemic stroke population with or without a recent TIA (24 hours prior), established TIA (at least more than one month) or no TIA. The increasing odds of exclusion or inclusion in the sub-cohort for these groups were analyzed separately. A Hosmer-Lemeshow test examined the validity of the model, and the overall correct classification percentage as well as the area under the Receiver Operating Curve (ROC) for score prediction was determined. This allowed us to test the sensitivity, specificity and accuracy of our logistic model. Odds ratios (ORs) were determined from the logistic regression and significance was set at the probability level of 0.05 . The odds ratio values were then utilized to predict the increasing odds of exclusion of inclusion in the TIA-24hr-ischemic stroke patients. 


\section{Results}

In this study, a total of 6,315 ischemic stroke patients were identified. Of this cohort, 846 patients had a TIA within 24 hours prior to the ischemic stroke, whereas 5,469 did not. Table 1 presents the demographic and clinical variables of acute ischemic stroke patients with and without TIA within 24 hours prior to ischemic stroke. TIA-24hr-ischemic stroke patients were more likely to be white (82.2\% vs. $78.4 \%)$, with lower rates of atrial fibrillation (13.9\% vs $16.9 \%$ ) and alcohol abuse (3.7\% vs. $6.2 \%)$. The TIA-24hrischemic stroke group also demonstrated higher rates of carotid artery stenosis ( $7.9 \%$ vs $6.1 \%$ ) and dyslipidemia ( $58.2 \%$ vs $50.4 \%$ ). These patients presented with higher rates of previous stroke ( $32.4 \%$ vs. $26.0 \%$ ) and previous TIA more than 24 hours prior to stroke (16.5\% vs. $8.7 \%)$. Furthermore, this group was more likely to have PVD (9.9\% vs. $7.3 \%)$, but less likely to smoke (20.6\% vs. $27.2 \%)$. TIA-24hrischemic stroke patients were more likely to take anti-HTN medications (73.9\% vs. $69.4 \%)$, cholesterol reducers ( $53.9 \%$ vs. $44.4 \%$ ), diabetes medications ( $31.8 \%$ vs. $27.3 \%)$, and antidepressants $(15.5 \%$ vs. $13.0 \%)$. They presented with lower NIHSS scores (3.46 \pm 4.1 vs $8.28 \pm 8.24)$, lower total cholesterol (167.88 \pm 44.01 vs $171.84 \pm 51.28)$, lower LDL levels ( $98.22 \pm 36.56$ vs $104.62 \pm 41.29$ ), and lower blood glucose (138.59 \pm 76.92 vs $147.3 \pm 81.05)$. Finally, this group presented with a higher INR $(1.19 \pm 0.5$ vs $1.14 \pm 0.5)$ but had a lower initial platelet count ( $265.55 \pm 87.03$ vs $122016.09 \pm 132836.59)$, lower heart rate (78.02 \pm 14.86 vs $82 \pm 18.53)$, lower systolic blood pressure (148.61 \pm 27.88 vs $151.82 \pm 29.31$ ), and lower diastolic blood pressure (79.37 \pm 17.53 vs $82.44 \pm 19.12)$.

Table 2 presents the demographic and clinical variables of acute ischemic stroke patients with and without a TIA less than 24 hours who are divided into groups: those treated with rtPA and those without rtPA treatment. As shown in the table 2, TIA-24hr-ischemic stroke patients that received rtPA were younger ( $57.8 \pm 15.49$ vs $68.39 \pm 14.33$ ), with lower rates of atrial fibrillation $(0.0 \%$ vs $14.4 \%)$, but higher rates of alcohol abuse (12.0\% vs. $3.41 \%)$. TIA-24hr-ischemic stroke patients that received rtPA demonstrated higher rates of migraine ( $16.0 \%$ vs $2.8 \%$ ), obesity ( $68.0 \%$ vs $41.29 \%$ ), higher NIHSS scores $(6.16 \pm 5.46$ vs $3.36 \pm 4.02)$ but were more likely to have a lower INR $(0.98 \pm 0.06$ vs $1.19 \pm 0.5)$. The non-TIA $<24$-hour patients that received rtPA presented with lower rates of carotid artery stenosis (4.2\% vs $6.7 \%)$, but higher rates of depression (15.4\% vs. $12.5 \%)$. They demonstrated higher rates of dyslipidemia ( $52.8 \%$ vs $49.6 \%$ ), HRT (2.3\% vs $1.2 \%$ ), migraine (3.4\% vs $2.1 \%)$, obesity $(51.1 \%$ vs $39.4 \%)$, and previous TIAs (10.8\% vs. $8.1 \%)$, but were less likely to present with a previous stroke $(21.9 \%$ vs $27.4 \%)$, PVD (6.0\% vs $7.7 \%$ ), and chronic renal disease (6.0\% vs. $8.9 \%)$. The non-TIA $<24$ hours group was more likely to take cholesterol reducers ( $47.6 \%$ vs. $43.4 \%$ ) and antidepressants ( $16.7 \%$ vs. $11.8 \%)$, but less likely to take diabetes medications ( $24.9 \%$ vs. $28.1 \%$ ). They presented with higher NIHSS scores (10.55 \pm 8.18 vs $7.43 \pm 8.11$ ) but were more likely to have lower total cholesterol (168.66 \pm 46.48 vs $173.01 \pm 53.6)$. They have lower LDL levels $(102.52 \pm 39.07$ vs $105.39 \pm 42.06)$, lower lipids $(6.25 \pm 1.6$ vs $6.64 \pm 2.83)$, lower blood glucose (141.29 \pm 74.84 vs $149.22 \pm 82.86)$, lower serum creatinine (1.14 \pm 0.75 vs $1.34 \pm 1.27$ ), but higher initial platelet counts (174859.69 \pm 128632.87 vs $36527.8 \pm 87310.62)$.

The results of logistic regression showing factors associated with rtPA in the TIA-24hr-ischemic stroke population is presented in Table 3, while the forest plot representation is shown in Fig 1 . The results 
indicate that TIA-24hr-ischemic stroke patients presenting with a history of alcohol abuse $(\mathrm{OR}=5.525$, $95 \% \mathrm{Cl}, 1.003-30.434, \mathrm{p}=0.05)$, migraine (OR=4.277, 95\% Cl, 1.095-16.703, $\mathrm{p}=0.037)$, and NIHSS score $(\mathrm{OR}=1.156,95 \% \mathrm{Cl}, 1.058-1.263, \mathrm{p}=0.001)$ were associated with increasing odds of receiving rtPA. Increasing age $(\mathrm{OR}=0.965,95 \% \mathrm{Cl}, 0.934-0.997, \mathrm{P}=0.033)$ and $\mathrm{INR}(\mathrm{OR}=0.113,95 \% \mathrm{Cl}, 0.013-1.006, \mathrm{p}=$ 0.51 ) were associated with increasing odds of exclusion from rtPA treatment. The ROC curve for the predictive power of the regression model is presented in Fig. 2. The discriminating capability of the model was very strong, as shown by the ROC curve, with area under the curve (AUROC) of AUROC $=0.895$ (95\% $\mathrm{Cl}, 0.824-0.966, \mathrm{P}<0.001)$.

Table 4 presents factors that are associated with the odds of receiving rtPA in the non-TIA $<24$ hours group, while the representative forest plot is shown in Fig 3. As shown in Table 4, HRT (OR $=1.79,95 \%$ $\mathrm{Cl}, 1.0-3.204, \mathrm{p}=0.05)$, obesity (OR=1.57, $95 \% \mathrm{Cl}, 1.342-1.838, \mathrm{p}<0.001)$, history of previous TIA $(\mathrm{OR}=1.488,95 \% \mathrm{Cl}, 1.15-1.924, \mathrm{p}=0.003)$, NIHSS score $(\mathrm{OR}=1.066,95 \% \mathrm{Cl}, 1.056-1.077, \mathrm{p}<0.001)$, use of cholesterol reducers $(\mathrm{OR}=1.286,95 \% \mathrm{Cl}, 1.089-1.52, \mathrm{p}=0.003)$, and anti-depressant use $(\mathrm{OR}=1.314,95 \%$ $\mathrm{Cl}, 1.057-1.633, \mathrm{p}=0.014)$ were associated with the increasing odds of receiving rtPA therapy. Increasing age $(\mathrm{OR}=0.99,95 \% \mathrm{Cl}, 0.984-0.995, \mathrm{P}<0.001)$, females $(\mathrm{OR}=0.756,95 \% \mathrm{Cl}, 0.645-0.886, \mathrm{p}=0.001)$, history of carotid artery stenosis $(\mathrm{OR}=0.626,95 \% \mathrm{Cl}, 0.436-0.897, \mathrm{p}=0.011)$, history of diabetes $(\mathrm{OR}=0.781,95 \% \mathrm{Cl}, 0.661-0.924, \mathrm{p}=0.004)$, alcohol abuse $(\mathrm{OR}=0.704,95 \% \mathrm{Cl}, 0.51-0.972, \mathrm{p}=0.033)$, history of previous stroke $(\mathrm{OR}=0.711,95 \% \mathrm{Cl}, 0.593-0.852, \mathrm{p}<0.001)$, total cholesterol $(\mathrm{OR}=0.998,95 \% \mathrm{Cl}$, 0.996-1.0, $p=0.014)$, serum creatinine $(\mathrm{OR}=0.838,95 \% \mathrm{Cl}, 0.755-0.931, \mathrm{p}=0.001), \mathrm{INR}(\mathrm{OR}=0.141,95 \% \mathrm{Cl}$, $0.086-0.233, p<0.001)$, and systolic blood pressure ( $\mathrm{OR}=0.997,95 \% \mathrm{Cl}, 0.994-0.999, \mathrm{p}=0.019)$ were associated with not receiving rtPA. As presented in Fig. 4, the predictive power of the logistic regression was strong. The area under the curve (AUROC) is $0.704(95 \% \mathrm{Cl}, 0.686-0.722, \mathrm{P}<0.001)$.

\section{Discussion}

The current study investigated clinical risk factors associated with inclusion or exclusion from rtPA therapy in an ischemic stroke population presenting with a TIA within 24 hours preceding an acute ischemic stroke. First, a frequency of only $13 \%$ of an antecedent TIA within 24 hours in the ischemic stroke population was found. Second, a greater percentage of TIA-24hr-ischemic stroke patients were excluded from rtPA when compared to the non-TIA <24-hour patients. Third, more clinical risk factors were associated with inclusion than exclusion for rtPA, while increasing age and INR were associated with increasing odds of exclusion from thrombolytic therapy in the TIA-24hr-ischemic stroke patients. Finally, more clinical risk factors were associated with exclusion than inclusion from rtPA in the ischemic stroke population in the non-TIA $<24$-hour group.

The non-TIA <24-hour ischemic stroke group analyzed in this study was older (68.08 \pm 14.47$)$ than patients reported in other studies (mean age of 63) [1]. Moreover, the TIA-24hr-ischemic stroke population 
in this study consists of a significant proportion of patients $>80$ years, not excluded from rtPA in line with AHA guidelines [24] and reported to be safe by several studies [25-27]. The prevalence of a prior TIA in patients with ischemic stroke in the general population is between $7 \%$ to $40 \%[13,28,29]$. The frequency of occurrence of a TIA in our TIA-24hr-ischemic population was $13 \%$, which falls within the low range of occurrence among those reported $[13,28,29]$. The occurrence of a TIA within 24 hours preceding the onset of acute ischemic stroke was not a contraindication for thrombolytic therapy in this study population, therefore, it is not possible that the exclusion of this group of patients is the reason for the low occurrence of TIAs observed. Since this is a retrospective study, there is the possibility of bias in data input which could potentially account for the low occurrence. However, the analysis of TIAs occurring within 24 hours preceding the onset of acute ischemic stroke is mainly done by retrospective data analysis, and this method is supported by several studies as the best approach to determine an antecedent TIA.[30, 31]. It is also possible that the main etiology of the ischemic stroke population with a TIA in this study is cardioembolism, which is often more severe than atherothrombotic strokes [1, 2]. Therefore, the low frequency could be attributed to lesser occurrence of stroke in a large vessel, which is more commonly indicated by temporary symptoms in contrast to stroke from cardioembolism[1].

The univariate analysis revealed that the TIA-ischemic stroke population that received rtPA was younger, more likely to have atrial fibrillation, have a history of alcohol abuse, be obese, present with a migraine, and have lower INR and NIH scores. Ischemic stroke patients receiving rtPA without a diagnosed TIA were younger, more likely to be depressed, have dyslipidemia, be on hormonal replacement therapy, present with a migraine, have a previous TIA, be obese, use cholesterol reducers or antidepressants, and have higher $\mathrm{NIH}$ scores. Following adjustment for the effect of confounding variables, hormonal replacement therapy, obesity, history of a previous TIA, and anti-depressant use were factors found to be associated with inclusion for rtPA in the non-TIA <24-hour patients, while increasing age, female gender, carotid artery stenosis, diabetes, history of previous stroke and alcohol use, cholesterol, serum creatinine, INR, and increased systolic blood pressure were associated with exclusion from rtPA. The identified comorbidities associated with exclusion from thrombolytic therapy are comparable to existing prospective and retrospective studies, such as increasing age associated with worse outcomes[32], female gender corresponding with significantly higher percentages of cardioembolic strokes[33], and severe carotid artery stenosis, which predicts poor outcome[34]. Other identified comorbidities reported in previous studies are diabetes; due to hyperglycemia, which increases the risk of cerebral hemorrhage with rtPA treatment[35], and chronic alcohol use; which increases excitotoxic/ischemic damage, leading to poor outcomes[36]. History of previous stroke represents an exclusion criteria, especially in patients with large infarctions and concern of bleeding[37]. Furthermore, high levels of serum creatinine as an exclusion criteria is due to risk of symptomatic intracranial hemorrhage[38], while elevated INR is due to the risk of intracranial hemorrhage[39]. Finally, higher peak values of systolic blood pressure may lead to higher rates of hemorrhagic complications[40].

A transient ischemic attack preceding ischemic stroke does not appear to have a major influence on outcomes following rtPA, and may actually induce neuroprotection in patients with ischemic stroke[41]. This argues for the necessity to understand the other clinical risk factors which might affect thrombolytic 
treatment outcome. This study revealed that TIA-24hr-ischemic stroke patients with a history of alcohol abuse are more likely to be included for rtPA. Alcohol consumption as a risk factor for stroke is known to follow a J-shaped curve, such that modest drinkers ( $<15 \mathrm{~g} / \mathrm{d}$ ) have the lowest risk, and heavy drinkers $(>60 \mathrm{~g} / \mathrm{d}$ ) have the highest[42]. The signs and symptoms of acute alcohol intoxication are similar to those of vertebrobasilar stroke[43]. Due to similarities in symptoms such as double vision, nystagmus, dysarthria, and ataxia, the differential diagnosis of alcohol intoxication versus vertebrobasilar stroke may constitute a major diagnostic challenge. Moreover, if alcohol intoxication and stroke occur concurrently, the signs and symptoms of stroke may be linked to the effects of alcohol, resulting in a delayed stroke diagnosis and failure to administer thrombolytic therapy. In the case of uncertainty, and if stroke cannot be excluded, thrombolytic therapy can be administered[43]. It is possible that the TIA-24hr-ischemic stroke patients with a history of alcohol abuse arrived at the hospital early, allowing stroke diagnosis to be established within the therapeutic time window. Therefore, the TIA-24hr-ischemic stroke patients with a simultaneous history of alcohol abuse were more likely to be eligible for rtPA therapy.

Furthermore, the TIA-24hr-ischemic stroke patients that presented with migraine were more likely to receive rtPA therapy. Migraine has been established as the third most common stroke mimic and contributes to greater than $17 \%$ of poor outcomes in thrombolytic therapy[44]. Thrombolytic therapy in ischemic stroke patients with migraine is associated with a low risk of poor treatment outcome[44]. With an increased capability of accurately diagnosing a migraine attack, it is possible that a comprehensive clinical evaluation provided an accurate diagnosis of migraine with existing history in the TIA-ischemic stroke patients in this study. Even when a definitive diagnosis is not possible, the evidence of rtPA safety in scientific literature[45-49] supports its administration, as shown in the current study.

Another major finding in this study is that older TIA-24hr-ischemic stroke patients are more likely to be excluded from rtPA. A TIA is known to have negligible effects on patients 50 years below, but significantly reduces life expectancy in individuals 65 years and older[50]. Compared to patients 50 years and younger, patients that are 75-84 years old are at a greater risk. Furthermore, patients above the age of 80 have the highest risk[50]. In line with this finding, the study showed that elderly stroke patients with a TIA within 24 hours prior to stroke may be excluded from rtPA therapy, suggesting that these patients may have the most to gain from intensive cerebrovascular risk management.

A major challenge with a TIA is the uncertainty of its diagnosis, including the neurovascular implication, which is systemic in many TIA studies[51]. More than $25 \%$ of patients assumed to present with a TIA in the emergency department were further assessed and noted to have had a stroke, while $25 \%$ had an established mimic condition[52]. While we could not dependably differentiate among stroke cases misclassified as a TIA, or complications of stroke mimicking a TIA in our retrospective data, our sample best represents those progressing to stroke after a TIA presentation assessed by DW-MRI prior to onset of ischemic stroke. Therefore, our retrospective data consist of ischemic stroke patients diagnosed with a TIA within 24 hours prior to onset of ischemic stroke, reflecting real world clinical scenarios. It has been shown that an estimated $70 \%$ of patients with a diagnosis of a TIA are admitted to the hospital and, of these, only $50 \%$ retain a TIA diagnosis[52, 53]. The studied cohort represents those retaining a TIA 
diagnosis within 24 hours prior to stroke, reducing misclassification. A major limitation of this study is that the results cannot be generalized to ischemic stroke patients with a TIA diagnosis greater than 24 hours prior to stroke. In addition, the small number of ischemic stroke patients having a TIA within 24 hours prior to onset of stroke could be considered another limitation of the study in the demonstration of differences in clinical risk factors between ischemic stroke with a TIA $<24$ hours prior and ischemic stroke without a TIA $<24$ hours prior. However, in the light of $13 \%$ occurrence of a TIA $<24$ hours prior to ischemic stroke in this population, which fits within the existing range of between $7 \%$ to $40 \%[1,2,28]$, it seems likely that these findings will be clinically relevant in decision making with respect to the management of clinical risk factors associated with thrombolytic therapy.

\section{Conclusion}

Patients presenting with a TIA less than 24 hours prior to an ischemic stroke were more likely to be excluded from receiving rtPA than those without a TIA 24 hours prior, with the most likely cause of exclusion criteria being increased age. Considering the small number of patients presenting with a TIA within 24 hours prior to an ischemic stroke and the high exclusion rate from rtPA within this group, this study provides vital information that can help facilitate future clinical decisions when administering rtPA to TIA-24hr-ischemic stroke patients.

\section{Declarations}

Ethics approval and consent to participate. This is a retrospective data collection. This study was approved by the institutional review board of PRISMA Health institutional committee for ethics (approval number: 00052571)

Acknowledgement. We thank the stroke unit of Greenville Health system for helping in the data collection.

Authors' contribution. NP, DS and TIN designed the concept, experimental design and data analysis, while TM and AS critically revised the drafts, interprets the results, read and approved the last version of this manuscript. All authors have provided the corresponding author with permission to be named in the manuscript and approved the submission of this manuscript.

Availability of data and materials. The retrospective datasets are available by request from the corresponding author of this manuscript respectively

Funding: This study was funded by the Fullerton Foundation.

Conflict of interest: None

Disclosure: Dr Thomas I Nathaniel is an associate Editor with BMC Neurology

\section{References}


[1] de Lecinana MA, Fuentes B, Masjuan J, Simal P, Diaz-Otero F, Reig G, et al. Thrombolytic therapy for acute ischemic stroke after recent transient ischemic attack. International Journal of Stroke 2012;7(3):213-8.

[2] McKinney JS, Masjuan J, Purroy F, Calvet D, Ay H, Cucchiara BL. Safety of Thrombolytic Therapy for Acute Ischemic Stroke after Recent Transient Ischemic Attack. Journal of Stroke \& Cerebrovascular Diseases 2012;21(7):551-4.

[3] Capone FT, Cavallari M, Casolla B, Caselli G, Pieroni A, Di Lazzaro V, et al. Stroke Prediction after Transient Ischemic Attacks in Patients Admitted to a Stroke Unit. European neurology 2012;67(1):34-8.

[4] Chang BP, Rostanski S, Willey J, Kummer B, Miller E, Elkind M. CAN I SEND This patient with stroke home? Strategies managing transient ischemic attack and minor stroke in the emergency department. Journal of Emergency Medicine 2018;54(5):636-44.

[5] Gupta HV, Farrell AM, Mittal MK. Transient ischemic attacks: predictability of future ischemic stroke or transient ischemic attack events. Therapeutics and Clinical Risk Management 2014;10:27-35.

[6] Sorensen AG, Ay H. Transient Ischemic Attack: Definition, Diagnosis, and Risk Stratification. Neuroimaging Clinics of North America 2011;21(2):303-.

[7] Siket MS, Edlow JA. Transient ischemic Attack Reviewing the Evolution of the Definition, Diagnosis, Risk Stratification, and Management for the Emergency Physician. Emergency Medicine Clinics of North America 2012;30(3):745-.

[8] Mair G, Wardlaw JM. Imaging of acute stroke prior to treatment: current practice and evolving techniques. British Journal of Radiology 2014;87(1040).

[9] Werring DJ, Coward LJ, Losseff NA, Jager HR, Brown MM. Cerebral microbleeds are common in ischemic stroke but rare in TIA. Neurology 2005;65(12):1914-8.

[10] Forster A, Gass A, Kern R, Ay H, Chatzikonstantinou A, Hennerici MG, et al. Brain Imaging in Patients with Transient Ischemic Attack: A Comparison of Computed Tomography and Magnetic Resonance Imaging. European neurology 2012;67(3):136-41.

[11] Purroy F. Brain imaging in patients with transient ischemic attack. Journal of the neurological sciences 2015;357:E464-E5.

[12] Kostenko EV, Eneeva MA, Kravchenko VG. Problems of medical rehabilitation in patients after a transient ischemic attack. Bulletin of Russian State Medical University 2019(3):44-9.

[13] Lv YT, Han XJ, Song YL, Han Y, Zhou CS, Zhou D, et al. Toward neuroimaging-based network biomarkers for transient ischemic attack. Human Brain Mapping 2019;40(11):3347-61. 
[14] Rahman H, Khan SU, Nasir F, Hammad T, Meyer MA, Kaluski E. Optimal Duration of Aspirin Plus Clopidogrel After Ischemic Stroke or Transient Ischemic Attack A Systematic Review and Meta-Analysis. Stroke 2019;50(4):947-53.

[15] Sadighi A, Abedi V, Stanciu A, El Andary N, Banciu M, Holland N, et al. Six-Month Outcome of Transient Ischemic Attack and Its Mimics. Frontiers in Neurology 2019;10.

[16] Adams. Guidelines for the early management of adults with ischemic stroke: A guideline from the American Heart Association/American Stroke Association Stroke Council, Clinical Cardiology Council, Cardiovascular Radiology and intervention council, and the atherosclerotic peripheral vascular disease and quality of care outcomes in research interdisciplinary working groups (vol 38, pg 1655, 2007). Stroke 2007;38(6):E38-E.

[17] Asimos AW, Rosamond WD, Rose KM, Howard AG, Murphy CV, Tegeler CH, et al. MRI use in TIA patients: Variations by joint commission stroke center certification status and implications for a revised tissue-based definition of TIA. Stroke 2008;39(2):584-.

[18] Bang OY, Ovbiagele B, Kim JS. Nontraditional Risk Factors for Ischemic Stroke An Update. Stroke 2015;46(12):3571-8.

[19] Gainey J, Blum B, Bowie B, Cooley K, Madeline L, Ervin EL, et al. Stroke and dyslipidemia: clinical risk factors in the telestroke versus non-telestroke. Lipids in Health and Disease 2018;17.

[20] Gainey J, Brechtel L, Konklin S, Madeline E, Lowther E, Blum B, et al. In a stroke cohort with incident hypertension; are more women than men likely to be excluded from recombinant tissue-type Plasminogen Activator (rtPA)? Journal of the neurological sciences 2018;387(15):139-46.

[21] Gainey J, Wormack L, Brechtel L, Nathaniel. IT. A Functional Outcome Model for a Telestroke-guided Tissue Plasminogen Activator Treatment of Stroke Patients. Stroke;49(Suppl 1):P89.

[22] Nathaniel IT, Gainey J, Blum B, Montgomery C. Clinical Risk Factors in Thrombolysis therapy: Telestroke Versus Nontelestroke. Journal of stroke and Cerebrovascualr Disease 2018.

[23] Sauerbrei W, Royston P, Binder H. Selection of important variables and determination of functional form for continuous predictors in multivariable model building. Statistics in Medicine 2007;26(30):551228.

[24] McCoy CE, Langdorf MI, Lotfipour S. American Heart Association/American Stroke Association Deletes Sections from 2018 Stroke Guidelines. Western Journal of Emergency Medicine 2018;19(6):94751 .

[25] Bagoly Z, Szegedi I, Kalmandi R, Toth NK, Csiba L. Markers of Coagulation and Fibrinolysis Predicting the Outcome of Acute Ischemic Stroke Thrombolysis Treatment: A Review of the Literature. Frontiers in Neurology 2019;10. 
[26] Song XJ, Liu ZL, Zeng R, Liu CW, Ye W. The Efficacy and Safety of AngioJet Rheolytic Thrombectomy in the Treatment of Subacute Deep Venous Thrombosis in Lower Extremity. Annals of Vascular Surgery 2019;58:295-301.

[27] Miller D, J. , Simpson JR, Silver B. Safety of Thrombolysis in Acute Ischemic Stroke: A Review of Complications, Risk Factors, and Newer Technologies. Neurohospitalist 2011 2011;13:138-47.

[28] Schaller B. Ischemic preconditioning as induction of ischemic tolerance after transient ischemic attacks in human brain: its clinical relevance. Neuroscience Letters 2005;377(3):206-11.

[29] Tse D, Hill MD, Coutts SB. Early Secondary Prevention in Transient Ischemic Attack (TIA) and Minor Stroke. Current Neurology and Neuroscience Reports 2019;19(6).

[30] Sobolewski P, Brola W, Wiszniewska M, Szczuchniak W, Fudala M, Domagalski M, et al. Intravenous thrombolysis with rt-PA for acute ischemic stroke within $24 \mathrm{~h}$ of a transient ischemic attack. J Neurol Sci 2014;340(1):44-9.

[31] Erdur H, Scheitz JF, Ebinger M, Rocco A, Grittner U, Meisel A, et al. In-Hospital Stroke Recurrence and Stroke After Transient Ischemic Attack Frequency and Risk Factors. Stroke 2015;46(4):1031-+.

[32] Clark WM, Wissman S, Albers GW, Jhamandas JH, Madden KP, Hamilton S, et al. Recombinant tissue-type plasminogen activator (alteplase) for ischemic stroke 3 to 5 hours after symptom onset - The ATLANTIS study: A randomized controlled trial. Jama-Journal of the American Medical Association 1999;282(21):2019-26.

[33] Roquer J, Campello AR, Gomis M. Sex differences in first-ever acute stroke. Stroke 2003;34(7):15815 .

[34] Tomkins AJ, Hood RJ, Pepperall D, Null CL, Levi CR, Spratt NJ. Thrombolytic Recanalization of Carotid Arteries Is Highly Dependent on Degree of Stenosis, Despite Sonothrombolysis. Journal of the American Heart Association 2016;5(2).

[35] Hafez S, Coucha M, Bruno A, Fagan SC, Ergul A. Hyperglycemia, Acute Ischemic Stroke, and Thrombolytic Therapy. Translational Stroke Research 2014;5(4):442-53.

[36] Xu GD, Li C, Parsiola AL, Li JY, McCarter KD, Shi RH, et al. Dose-Dependent Influences of Ethanol on Ischemic Stroke: Role of Inflammation. Frontiers in Cellular Neuroscience 2019;13.

[37] Colello MJ, Ivey LE, Gainey J, Faulkner RV, Johnson A, Brechtel L, et al. Pharmacological thrombolysis for acute ischemic stroke treatment: Gender differences in clinical risk factors. Advances in Medical Sciences 2018;63(1):100-6.

[38] Marsh EB, Gottesman RF, Hillis AE, Urrutia VC, Llinas RH. Serum Creatinine May Indicate Risk of Symptomatic Intracranial Hemorrhage After Intravenous Tissue Plasminogen Activator (IV tPA). Medicine 
2013;92(6):317-23.

[39] Gulati D, Dua D, Torbey MT. Hemostasis in Intracranial Hemorrhage. Frontiers in Neurology 2017;8.

[40] Mistry EA, Mistry AM, Nakawah MO, Khattar NK, Fortuny EM, Cruz AS, et al. Systolic Blood Pressure Within 24 Hours After Thrombectomy for Acute Ischemic Stroke Correlates With Outcome. Journal of the American Heart Association 2017;6(5).

[41] Wang WW, Chen DZ, Zhao M, Yang XF, Gong DR. Prior transient ischemic attacks may have a neuroprotective effect in patients with ischemic stroke. Archives of Medical Science 2017;13(5):1057-61.

[42] Dawson DA. Defining Risk Drinking. Alcohol Research \& Health 2011;34(2):144-56.

[43] Arokszallasi T, Balogh E, Csiba L, Fekete I, Fekete K, Olah L. Acute alcohol intoxication may cause delay in stroke treatment - case reports. BMC neurology 2019;19.

[44] Terrin A, Toldo G, Ermani M, Mainardi F, Maggioni F. When migraine mimics stroke: A systematic review. Cephalalgia 2018;38(14):2068-78.

[45] Daniere F, Edjtati-Goujon M, Metterio C, Turc G, Naggara O, Tsetikas L, et al. MR screening of candidates for thrombolysis: How to identify stroke mimics? Journal of Neuroradiology 2014;41(5):28395.

[46] Demaerschalk BM, Kleindorfer DO, Adeoye OM, Demchuk AM, Fugate JE, Grotta JC, et al. Scientific Rationale for the Inclusion and Exclusion Criteria for Intravenous Alteplase in Acute Ischemic Stroke A Statement for Healthcare Professionals From the American Heart Association/American Stroke Association. Stroke 2016;47(2):581-+.

[47] Erbguth F. Stroke Mimics and Stroke Chameleons - Differential Diagnosis of the Stroke. Fortschritte Der Neurologie Psychiatrie 2017;85(12):747-62.

[48] Kostulas N, Larsson M, Kall TB, von Euler M, Nathanson D. Safety of thrombolysis in stroke mimics: an observational cohort study from an urban teaching hospital in Sweden. Bmj Open 2017;7(10).

[49] Zinkstok SM, Engelter ST, Gensicke H, Lyrer PA, Ringleb PA, Artto V, et al. Safety of Thrombolysis in Stroke Mimics Results From a Multicenter Cohort Study. Stroke 2013;44(4):1080-+.

[50] Gattellari M, Goumas C, Garden F, Worthington JM. Relative Survival After Transient Ischaemic Attack Results From the Program of Research Informing Stroke Management (PRISM) Study. Stroke 2012;43(1):79-U179.

[51] Johnston SC, Rothwell PM, Nguyen-Huynh MN, Giles MF, Elkins JS, Bernstein AL, et al. Validation and refinement of scores to predict very early stroke risk after transient ischaemic attack. Lancet 2007;369(9558):283-92. 
[52] Perry JJ, Sharma M, Sivilotti MLA, Sutherland J, Symington C, Worster A, et al. Prospective validation of the ABCD2 score for patients in the emergency department with transient ischemic attack. Canadian Medical Association Journal 2011;183(10):1137-45.

[53] Hill MD, Yiannakoulias N, Jeerakathil T, Tu JV, Svenson LW, Schopflocher DP. The high risk of stroke immediately after transient ischemic attack - A population-based study. Neurology 2004;62(11):2015-20.

\section{Tables}




\begin{tabular}{|c|c|c|c|}
\hline $\begin{array}{l}\text { Demographic and clinical } \\
\text { factors }\end{array}$ & $\begin{array}{l}\text { Acute Ischemic Stroke with TIA } \\
\qquad 24 \text { hours }\end{array}$ & $\begin{array}{l}\text { Acute Ischemic Stroke without TIA } \\
\qquad<24 \text { hours }\end{array}$ & \\
\hline $\begin{array}{l}\text { Number of patients } \\
\text { Age Group: No. (\%) }\end{array}$ & 846 & 5469 & P-value \\
\hline$<50$ & 97 (11.5) & $658(12.0)$ & 0.299 \\
\hline $50-59$ & $131(15.5)$ & $996(18.2)$ & \\
\hline $60-69$ & 206 (24.3) & 1299 (23.8) & \\
\hline $70-79$ & $195(23.0)$ & $1231(22.5)$ & \\
\hline$>=80$ & 217 (25.7) & 1285 (23.5) & \\
\hline Mean \pm SD & $68.08 \pm 14.47$ & $67.25 \pm 14.73$ & 0.126 \\
\hline \multicolumn{4}{|l|}{ Race: No (\%) } \\
\hline White & $695(82.2)$ & 4288 (78.4) & $0.042 * a$ \\
\hline Black & $130(15.4)$ & $1002(18.3)$ & \\
\hline Other & $21(2.5)$ & $179(3.3)$ & \\
\hline \multicolumn{4}{|l|}{ Gender: No. (\%) } \\
\hline Female & 451 (53.3) & 2807 (51.3) & 0.283 \\
\hline Male & $395(46.7)$ & 2662 (48.7) & \\
\hline \multicolumn{4}{|l|}{ Medical History: No. (\%) } \\
\hline Atrial Fib & 118 (13.9) & 924 (16.9) & $0.032 * \mathrm{a}$ \\
\hline Coronary Artery Disease & $283(33.5)$ & 1661 (30.4) & 0.71 \\
\hline Carotid Artery Stenosis & $67(7.9)$ & $334(6.1)$ & $0.44^{* a}$ \\
\hline Depression & $125(14.8)$ & $721(13.2)$ & 0.206 \\
\hline Diabetes & $320(37.8)$ & 1935 (35.4) & 0.167 \\
\hline Drugs or Alcohol & $31(3.7)$ & $337(6.2)$ & $0.004^{* a}$ \\
\hline Dyslipidemia & $492(58.2)$ & 2755 (50.4) & $<0.001 * a$ \\
\hline Stroke Family History & $87(10.3)$ & $494(9.0)$ & 0.241 \\
\hline Heart Failure & $85(10.0)$ & $590(10.8)$ & 0.516 \\
\hline $\begin{array}{l}\text { Hormonal Replacement } \\
\text { Therapy }\end{array}$ & $11(1.3)$ & $79(1.4)$ & 0.742 \\
\hline Hypertension & 675 (79.8) & 4306 (5469) & 0.485 \\
\hline Migraine & $27(3.2)$ & $134(2.5)$ & 0.203 \\
\hline Obesity & $356(42.1)$ & $2311(42.3)$ & 0.923 \\
\hline Previous Stroke & $274(32.4)$ & $1424(26.0)$ & $<0.001 * a$ \\
\hline Previous TIA & 140 (16.5) & 477 (8.7) & $<0.001 * a$ \\
\hline Prosthetic Heart Valve & $11(1.3)$ & $62(1.1)$ & 0.673 \\
\hline $\begin{array}{l}\text { Peripheral Vascular } \\
\text { Disease }\end{array}$ & $84(9.9)$ & $400(7.3)$ & $0.008^{* a}$ \\
\hline Chronic Renal Disease & $66(7.8)$ & 447 (8.2) & 0.713 \\
\hline Sickle Cell & $1(0.1)$ & $4(0.1)$ & 0.665 \\
\hline Sleep Apnea & $34(4.0)$ & $170(3.1)$ & 0.163 \\
\hline Smoker & $174(20.6)$ & $1486(27.2)$ & $<0.001 * a$ \\
\hline \multicolumn{4}{|l|}{$\begin{array}{l}\text { Medication History: No } \\
\text { (\%) }\end{array}$} \\
\hline HTN medication & 625 (73.9) & 3794 (69.4) & $0.008^{* a}$ \\
\hline Cholesterol Reducer & 456 (53.9) & $2428(44.4)$ & $<0.001 * a$ \\
\hline Diabetes medication & 269 (31.8) & 1495 (27.3) & $0.007 * \mathrm{a}$ \\
\hline
\end{tabular}


(\%)

\begin{tabular}{lccr}
$0-9$ & $677(90.6)$ & $3289(71.7)$ & $<0.001^{*}$ \\
$10-14$ & $53(7.1)$ & $507(11.1)$ & \\
$15-20$ & $12(1.6)$ & $501(10.9)$ & $<0.001^{* b}$ \\
$21-25$ & $5(0.7)$ & $8.28 \pm 8.24$ & $0.026^{* b}$ \\
Mean \pm SD & $3.46 \pm 4.1$ & $171.84 \pm 51.82$ & 0.1 \\
\hline Lab values: Mean \pm SD & & $139.64 \pm 105.16$ & 0.062 \\
\hline Total cholesterol & $167.88 \pm 44.01$ & $41.78 \pm 13.84$ & $<0.001^{* b}$ \\
\hline Triglycerides & $146.38 \pm 93.94$ & $104.62 \pm 41.29$ & 0.389 \\
\hline HDL & $42.81 \pm 14.28$ & $6.53 \pm 2.56$ & $0.004^{* b}$ \\
\hline LDL & $98.22 \pm 36.56$ & $147.3 \pm 81.05$ & 0.288 \\
\hline Lipids & $7.38 \pm 26.21$ & $1.29 \pm 1.17$ & $<0.001^{* b}$ \\
Blood Glucose & $138.59 \pm 76.92$ & $122016.09 \pm 132836.59$ & $0.036^{* b}$ \\
\hline Serum Creatinine & $1.44 \pm 3.45$ & $1.14 \pm 0.5$ & $<0.001^{* b}$ \\
Initial Platelet Count & $265.55 \pm 87.03$ & & $0.003^{* b}$ \\
INR & $1.19 \pm 0.5$ & $82 \pm 18.53$ & $<0.001^{* b}$ \\
\hline Vital Signs: Mean \pm SD & & $151.82 \pm 29.31$ & $82.44 \pm 19.12$ \\
\hline Heart Rate & $78.02 \pm 14.86$ & & \\
\hline Blood Pressure Systolic & $148.61 \pm 27.88$ & & \\
Blood Pressure Diastolic & $79.37 \pm 17.53$ & & \\
\hline
\end{tabular}

Notes:

aPearson's Chi-Squared test

bStudent's T test

* $P$-value $<0.05$

Table 1. 


\begin{tabular}{|c|c|c|c|c|c|c|}
\hline \multirow[b]{2}{*}{$\begin{array}{l}\text { Demographic and } \\
\text { clinical factors }\end{array}$} & \multicolumn{2}{|c|}{$\begin{array}{c}\text { Acute Ischemic Stroke } \\
\text { with TIA }<24 \text { hours }\end{array}$} & & \multicolumn{2}{|c|}{$\begin{array}{l}\text { Acute Ischemic Stroke } \\
\text { without TIA }<24 \text { hours }\end{array}$} & \\
\hline & $\begin{array}{l}\text { No rtPA } \\
\text { Group }\end{array}$ & rtPA Group & & No rtPA Group & rtPA Group & \\
\hline $\begin{array}{l}\text { Number of patients } \\
\text { Age Group: No. (\%) }\end{array}$ & 821 & 25 & P-value & 4142 & 1327 & P-Value \\
\hline$<50$ years & $89(10.84)$ & $8(32)$ & $0.004^{* a}$ & 467 (11.3) & $191(14.4)$ & $0.001 * a$ \\
\hline $50-59$ & 128 (15.59) & $3(12)$ & & 736 (17.8) & $260(19.6)$ & \\
\hline $60-69$ & 197 (23.99) & $9(36)$ & & 981 (23.7) & $318(24.0)$ & \\
\hline $70-79$ & 192 (23.38) & $3(12)$ & & $942(22.7)$ & $289(21.8)$ & \\
\hline$>=80$ & 215 (26.18) & $2(8)$ & & $1016(24.5)$ & $269(20.3)$ & \\
\hline Age Mean \pm SD & $\begin{array}{l}68.39 \pm \\
14.33\end{array}$ & $\begin{array}{l}57.8 \pm \\
15.49\end{array}$ & $<0.001 * b$ & $67.73 \pm 14.69$ & $65.76 \pm 14.78$ & $<0.001 * \mathrm{~b}$ \\
\hline \multicolumn{7}{|l|}{ Race: No (\%) } \\
\hline White & $675(82.21)$ & $20(80)$ & 0.878 & 3228 (77.9) & 1060 (79.9) & 0.313 \\
\hline Black & $126(15.34)$ & $4(16)$ & & $774(18.7)$ & $228(17.2)$ & \\
\hline Other & $20(2.43)$ & $1(4)$ & & $140(3.4)$ & 39 (2.9) & \\
\hline \multicolumn{7}{|l|}{ Gender: No. (\%) } \\
\hline Female & $437(53.2)$ & $14(56)$ & 0.784 & 2148 (51.9) & 659 (49.7) & 0.163 \\
\hline Male & 384 (46.77) & $11(44)$ & & $1994(48.1)$ & $668(50.3)$ & \\
\hline \multicolumn{7}{|l|}{$\begin{array}{l}\text { Medical History: No. } \\
\text { (\%) }\end{array}$} \\
\hline Atrial Fib & $118(14.4)$ & $0(0)$ & $0.041 * a$ & $713(17.2)$ & $211(15.9)$ & 0.266 \\
\hline $\begin{array}{l}\text { Coronary Artery } \\
\text { Disease }\end{array}$ & 275 (33.49) & $8(32)$ & 0.876 & $1262(30.5)$ & $399(30.1)$ & 0.782 \\
\hline $\begin{array}{l}\text { Carotid Artery } \\
\text { Stenosis }\end{array}$ & $65(7.91)$ & $2(8)$ & 0.988 & $278(6.7)$ & $56(4.2)$ & $0.001 * \mathrm{a}$ \\
\hline Depression & 119 (14.49) & $6(24)$ & 0.187 & $516(12.5)$ & $205(15.4)$ & $0.005^{* a}$ \\
\hline Diabetes & $310(37.75)$ & $10(40)$ & 0.820 & $1520(36.7)$ & 415 (31.3) & $<0.001 * a$ \\
\hline Drugs or Alcohol & $28(3.41)$ & $3(12)$ & $0.024^{* a}$ & $260(6.3)$ & $77(5.8)$ & 0.532 \\
\hline Dyslipidemia & 477 (58.09) & $15(60)$ & 0.850 & 2055 (49.6) & $700(52.8)$ & $0.047 * a$ \\
\hline $\begin{array}{l}\text { Stroke Family } \\
\text { History }\end{array}$ & $82(9.98)$ & $5(20)$ & 0.104 & 364 (8.8) & $130(9.8)$ & 0.265 \\
\hline Heart Failure & $83(10.1)$ & $2(8)$ & 0.730 & $453(10.9)$ & $137(10.3)$ & 0.531 \\
\hline $\begin{array}{l}\text { Hormonal } \\
\text { Replacement } \\
\text { Therapy }\end{array}$ & $11(1.33)$ & $0(0)$ & 0.560 & $48(1.2)$ & $31(2.3)$ & $0.002 * a$ \\
\hline Hypertension & 654 (79.65) & $21(84)$ & 0.594 & 3262 (78.8) & 1044 (78.7) & 0.950 \\
\hline Migraine & $23(2.8)$ & $4(16)$ & $0.001 * a$ & $89(2.1)$ & $45(3.4)$ & $0.011 * \mathrm{a}$ \\
\hline Obesity & 339 (41.29) & $17(68)$ & $0.008 * a$ & $1633(39.4)$ & $678(51.1)$ & $<0.001 * \mathrm{a}$ \\
\hline Previous Stroke & 265 (32.27) & $9(36)$ & 0.695 & $1134(27.4)$ & $290(21.9)$ & $<0.001 * \mathrm{a}$ \\
\hline Previous TIA & 135 (16.44) & $5(20)$ & 0.637 & $334(8.1)$ & $143(10.8)$ & $0.002 * \mathrm{a}$ \\
\hline $\begin{array}{l}\text { Prosthetic Heart } \\
\text { Valve }\end{array}$ & $11(1.33)$ & $0(0)$ & 0.560 & $52(1.3)$ & $10(0.8)$ & 0.133 \\
\hline $\begin{array}{l}\text { Peripheral Vascular } \\
\text { Disease }\end{array}$ & $83(10.1)$ & $1(4)$ & 0.314 & $321(7.7)$ & $79(6.0)$ & $0.029 * \mathrm{a}$ \\
\hline $\begin{array}{l}\text { Chronic Renal } \\
\text { Disease }\end{array}$ & $66(8.03)$ & $0(0)$ & 0.140 & 368 (8.9) & $79(6.0)$ & $0.001 * \mathrm{a}$ \\
\hline
\end{tabular}




\begin{tabular}{|c|c|c|c|c|c|c|}
\hline Sickle Cell & $1(0.12)$ & $0(0)$ & 0.861 & $4(0.1)$ & $0(0)$ & 0.257 \\
\hline Sleep Apnea & $32(3.89)$ & $2(8)$ & 0.304 & $125(3.0)$ & $45(3.4)$ & 0.495 \\
\hline Smoker & 169 (20.58) & $5(20)$ & 0.943 & 1098 (26.5) & $388(29.2)$ & 0.052 \\
\hline \multicolumn{7}{|l|}{$\begin{array}{l}\text { Medication History: } \\
\text { No (\%) }\end{array}$} \\
\hline HTN medication & 169 (20.58) & $5(20)$ & 0.828 & $2851(68.8)$ & $943(71.1)$ & 0.125 \\
\hline Cholesterol Reducer & 440 (53.59) & $16(64)$ & 0.304 & $1796(43.4)$ & $632(47.6)$ & $0.006 * \mathrm{a}$ \\
\hline Diabetes medication & $260(31.66)$ & $9(36)$ & 0.647 & $1164(28.1)$ & 331 (24.9) & $0.025^{* a}$ \\
\hline Antidepressant & $126(15.34)$ & $5(20)$ & 0.526 & 489 (11.8) & $222(16.7)$ & $<0.001 * a$ \\
\hline \multicolumn{7}{|l|}{$\begin{array}{l}\text { Initial NIHSS Score: } \\
\text { No (\%) }\end{array}$} \\
\hline $0-9$ & 658 (91.13) & $19(76)$ & $0.001 * a$ & 2556 (76.3) & $773(59.4)$ & $<0.001 * \mathrm{a}$ \\
\hline $10-14$ & $50(6.92)$ & $3(12)$ & & $308(9.2)$ & $199(16.1)$ & \\
\hline $15-20$ & $9(1.24)$ & $3(12)$ & & $308(9.2)$ & $193(15.6)$ & \\
\hline $21-25$ & $5(0.69)$ & $0(0)$ & & $180(5.4)$ & $110(8.9)$ & \\
\hline $\begin{array}{l}\text { NIHSS Score Mean } \\
\pm \text { SD }\end{array}$ & $3.36 \pm 4.02$ & $6.16 \pm 5.46$ & $0.018^{* b}$ & $7.43 \pm 8.11$ & $10.55 \pm 8.18$ & $<0.001 * b$ \\
\hline \multicolumn{7}{|l|}{$\begin{array}{l}\text { Lab values: Mean } \pm \\
\text { SD }\end{array}$} \\
\hline Total cholesterol & $\begin{array}{l}168.15 \pm \\
43.98\end{array}$ & $\begin{array}{l}159.45 \pm \\
44.73\end{array}$ & 0.341 & $173.01 \pm 53.6$ & $168.66 \pm 46.48$ & $0.006^{* b}$ \\
\hline Triglycerides & $\begin{array}{l}146.1 \pm \\
94.44\end{array}$ & $\begin{array}{l}154.79 \pm \\
78.82\end{array}$ & 0.656 & $139.25 \pm 104.13$ & $140.71 \pm 107.94$ & 0.674 \\
\hline HDL & $\begin{array}{l}42.78 \pm \\
14.33\end{array}$ & $\begin{array}{l}43.58 \pm \\
12.75\end{array}$ & 0.787 & $41.77 \pm 13.91$ & $41.8 \pm 13.65$ & 0.946 \\
\hline LDL & $98.46 \pm 36.6$ & $\begin{array}{l}90.79 \pm \\
35.42\end{array}$ & 0.312 & $105.39 \pm 42.06$ & $102.52 \pm 39.07$ & $0.029 * b$ \\
\hline Lipids & $7.4 \pm 26.61$ & $6.55 \pm 2$ & 0.881 & $6.64 \pm 2.83$ & $6.25 \pm 1.6$ & $<0.001 * b$ \\
\hline Blood Glucose & $\begin{array}{l}138.17 \pm \\
76.44\end{array}$ & $\begin{array}{l}152.16 \pm \\
91.72\end{array}$ & 0.371 & $149.22 \pm 82.86$ & $141.29 \pm 74.84$ & $0.001 * b$ \\
\hline Serum Creatinine & $1.45 \pm 3.5$ & $1.02 \pm 0.37$ & 0.547 & $1.34 \pm 1.27$ & $1.14 \pm 0.75$ & $<0.001 * b$ \\
\hline Initial Platelet Count & $\begin{array}{l}273.56 \pm \\
84.49\end{array}$ & $185.33 \pm 84$ & 0.094 & $\begin{array}{l}36527.8 \pm \\
87310.62\end{array}$ & $\begin{array}{l}174859.69 \pm \\
128632.87\end{array}$ & $<0.001 * b$ \\
\hline INR & $1.19 \pm 0.5$ & $0.98 \pm 0.06$ & $<0.001^{* b}$ & $1.17 \pm 0.57$ & $1.06 \pm 0.15$ & \\
\hline \multicolumn{7}{|l|}{$\begin{array}{l}\text { Vital Signs: Mean } \pm \\
\text { SD }\end{array}$} \\
\hline Heart Rate & $\begin{array}{l}77.97 \pm \\
14.83\end{array}$ & $\begin{array}{l}79.6 \pm \\
15.71\end{array}$ & 0.590 & $82.07 \pm 18.94$ & $81.81 \pm 17.18$ & 0.644 \\
\hline $\begin{array}{l}\text { Blood Pressure } \\
\text { Systolic }\end{array}$ & $\begin{array}{l}148.76 \pm \\
27.95\end{array}$ & $\begin{array}{l}143.6 \pm \\
25.05\end{array}$ & 0.362 & $151.99 \pm 30.04$ & $151.31 \pm 26.92$ & 0.439 \\
\hline $\begin{array}{l}\text { Blood Pressure } \\
\text { Diastolic }\end{array}$ & $\begin{array}{l}79.24 \pm \\
17.48 \\
\end{array}$ & $\begin{array}{l}83.4 \pm \\
18.56 \\
\end{array}$ & 0.243 & $82.29 \pm 19.38$ & $82.92 \pm 18.3$ & 0.277 \\
\hline
\end{tabular}

Notes:

apearson's Chi-Squared test

bStudent's T test 
$* P$-value $<0.05$

Table 2.

\begin{tabular}{lrrrrrr}
\hline & & & & \multicolumn{2}{c}{$95 \%$ C.I. } & \\
\cline { 5 - 6 } Demographic and clinical factors & B Value & Wald & Odds Ratio & Lower & Upper & $P$-value \\
\hline Increasing Age & -0.035 & 4.533 & 0.965 & 0.934 & 0.997 & $0.033^{*}$ \\
Drugs or Alcohol & 1.709 & 3.854 & 5.525 & 1.003 & 30.434 & $0.05^{*}$ \\
\hline Migraine & 1.453 & 4.371 & 4.277 & 1.095 & 16.703 & $0.037^{*}$ \\
\hline Obesity & 1.001 & 3.49 & 2.722 & 0.952 & 7.784 & 0.062 \\
\hline History of Smoking & -1.328 & 2.96 & 0.265 & 0.058 & 1.203 & 0.085 \\
\hline NIHSS & 0.145 & 10.37 & 1.156 & 1.058 & 1.263 & $0.001^{*}$ \\
\hline INR & -2.181 & 3.82 & 0.113 & 0.013 & 1.006 & 0.051 \\
\hline
\end{tabular}

Notes:

Backward Stepwise model based on Likelihood Ratio was applied.

Model assumptions were fulfilled.

Multicollinearity and interactions among independent variables were checked and no significant interactions were found.

Hosmer-Lemeshow test $(P=0.016)$, Cox \& Snell $\left(R^{2}=0.679\right)$

Table 3. 


\begin{tabular}{lrrrrrrr}
\hline & & & & \multicolumn{2}{c}{$95 \%$ C.I. } & \\
\cline { 5 - 6 } Demographic and clinical factors & B Value & Wald & Odds Ratio & Lower & Upper & P-value \\
\hline Increasing Age & -0.01 & 13.03 & 0.99 & 0.984 & 0.995 & $<0.001^{*}$ \\
Female & -0.28 & 11.977 & 0.756 & 0.645 & 0.886 & $0.001^{*}$ \\
\hline Carotid Artery Stenosis & -0.469 & 6.509 & 0.626 & 0.436 & 0.897 & $0.011^{*}$ \\
\hline Diabetes & -0.247 & 8.357 & 0.781 & 0.661 & 0.924 & $0.004^{*}$ \\
\hline Drugs or Alcohol & -0.351 & 4.548 & 0.704 & 0.51 & 0.972 & $0.033^{*}$ \\
\hline HRT & 0.582 & 3.842 & 1.79 & 1 & 3.204 & $0.05^{*}$ \\
\hline Obesity & 0.451 & 31.585 & 1.57 & 1.342 & 1.838 & $<0.001^{*}$ \\
\hline History of Previous Stroke & -0.341 & 13.608 & 0.711 & 0.593 & 0.852 & $<0.001^{*}$ \\
\hline History of Previous TIA & 0.397 & 9.133 & 1.488 & 1.15 & 1.924 & $0.003^{*}$ \\
\hline NIHSS & 0.064 & 168.417 & 1.066 & 1.056 & 1.077 & $<0.001^{*}$ \\
\hline Cholesterol Reducer & 0.252 & 8.759 & 1.286 & 1.089 & 1.52 & $0.003^{*}$ \\
\hline Anti-Depressant & 0.273 & 6.029 & 1.314 & 1.057 & 1.633 & $0.014^{*}$ \\
\hline Total Cholesterol & -0.002 & 6.06 & 0.998 & 0.996 & 1 & $0.014^{*}$ \\
\hline Serum Creatinine & -0.176 & 10.9 & 0.838 & 0.755 & 0.931 & $0.001^{*}$ \\
\hline INR & -1.956 & 58.726 & 0.141 & 0.086 & 0.233 & $<0.001^{*}$ \\
\hline Blood Pressure Systolic & -0.003 & 5.471 & 0.997 & 0.994 & 0.999 & $0.019^{*}$ \\
\hline
\end{tabular}

Notes:

Backward Stepwise model based on Likelihood Ratio was applied.

Model assumptions were fulfilled.

Multicollinearity and interactions among independent variables were checked and no significant interactions were found.

Hosmer-Lemeshow test $(P=0.006)$, Cox \& Snell $\left(R^{2}=0.102\right)$

Table 4.

Figures 


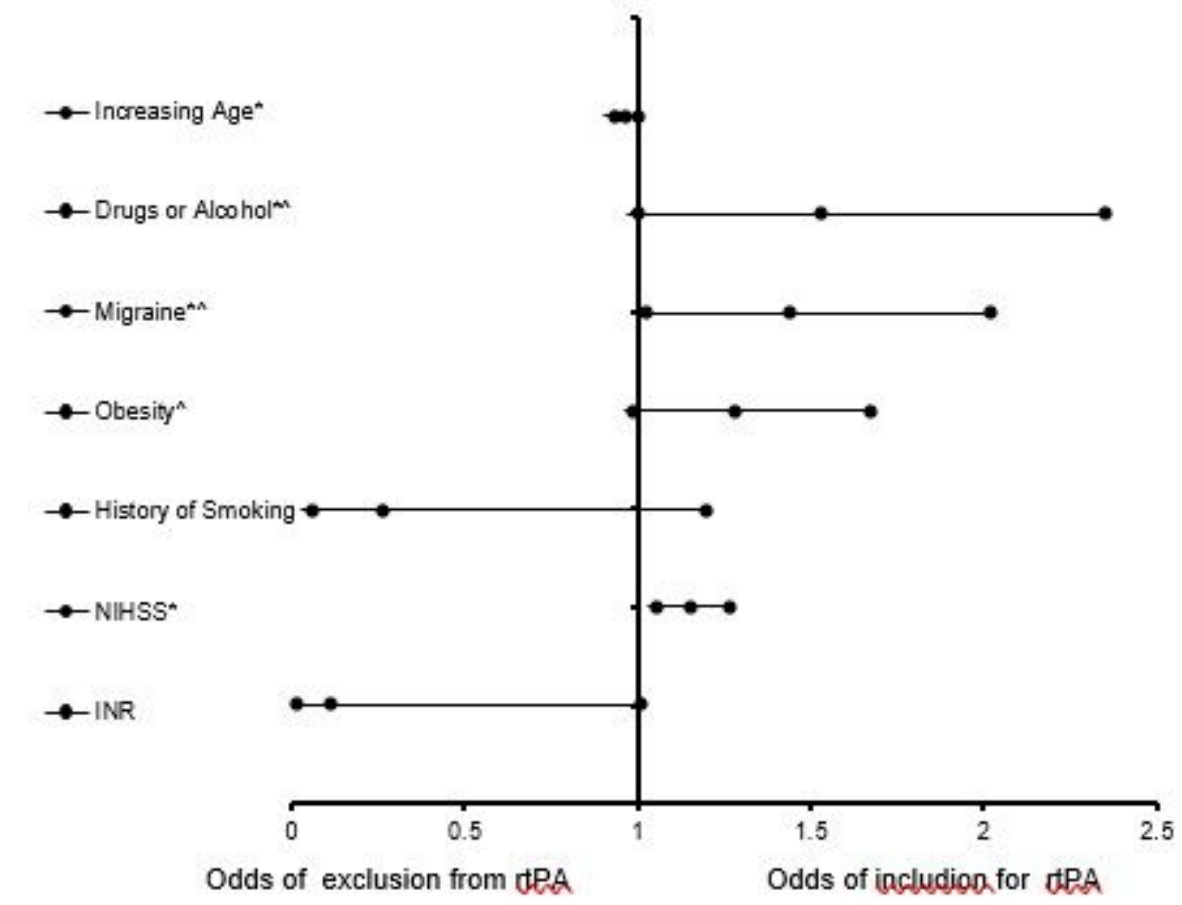

Figure 1

\section{Figure 1}

Forest Plot representation of Table 3. Confidence Interval band below 1 denotes factors that are associated with not receiving rtPA while Confidence Interval band above 1 denotes factors that are associated with receiving rtPA. Confidence Interval bands that cross 1 cannot be associated with either receiving or not receiving itPA. *Indicates statistical significance $(P<0.05)$ with a $95 \%$ confidence interval. 


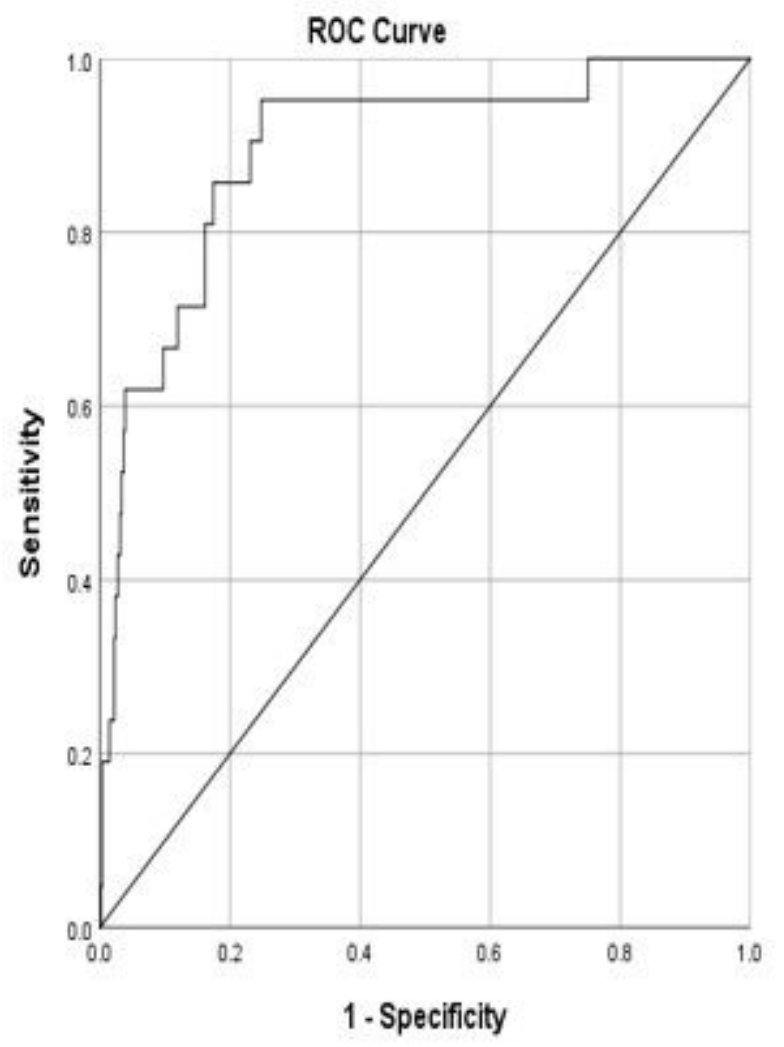

Figure 2:

\section{Figure 2}

ROC curve associated with prediction of receiving rtPA for acute ischemic stroke population with TIA $<24$ hours. Higher area under the curve (AUC) values in ROC analysis indicates better discrimination of the score for the measured outcome. Classification table (overall correctly classified percentage $=96.1 \%$ ) and area under the ROC curve (AUC $=0.895,0.824-0.966)$ were applied to check model fitness. 


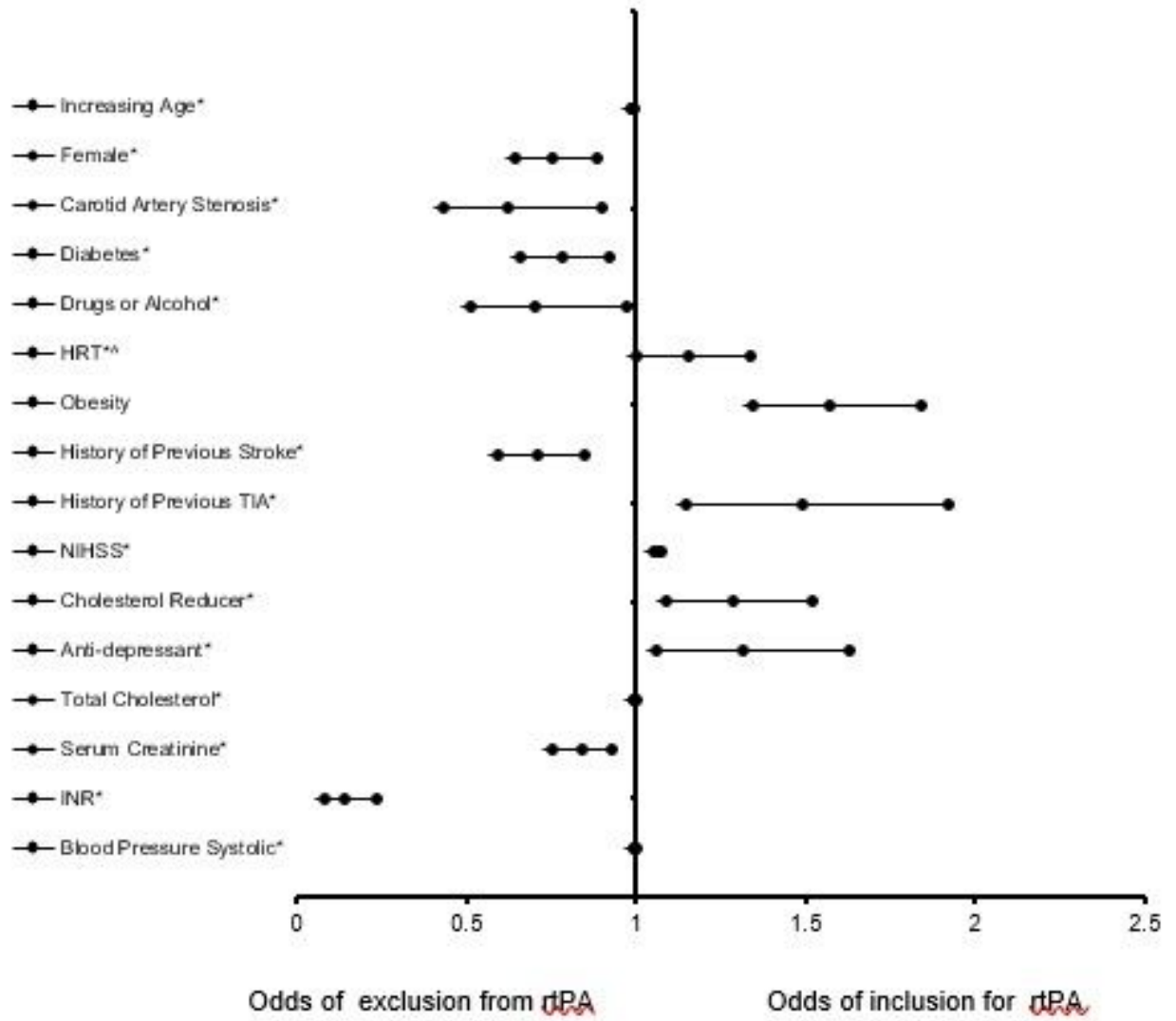

Figure 3:

Figure 3 


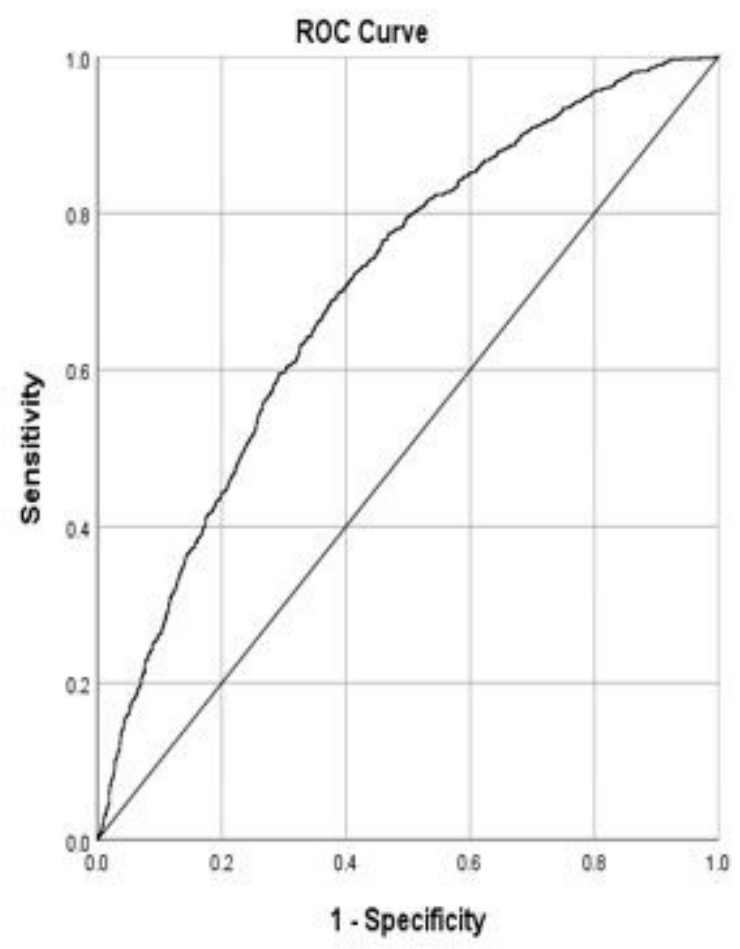

Figure 4:

\section{Figure 4}

ROC curve associated with prediction of receiving rtPA for acute ischemic stroke population without a TIA $<24$ hours. Higher area under the curve (AUC) values in ROC analysis indicates better discrimination of the score for the measured outcome. Classification table (overall correctly classified percentage $=70.2 \%$ ) and area under the ROC curve (AUC $=0.704,0.686-0.722)$ were applied to check model fitness. 